\title{
NATIONAL FUEL TYPE MAPPING METHODOLOGY USING GEOGRAPHIC OBJECT BASED IMAGE ANALYSIS AND LANDSAT 8 OLI IMAGERY.
}

\author{
M. Tompoulidou ${ }^{\text {a, } *}$, A. Stefanidou ${ }^{\text {a }}$, D. Grigoriadis ${ }^{\text {a }}$, E. Dragozi ${ }^{\text {a }}$, D. Stavrakoudis ${ }^{\text {a }}$, I.Z. Gitas ${ }^{\text {a }}$ \\ ${ }^{a}$ Forest Management and Remote Sensing Laboratory, Aristotle University of Thessaloniki 55124 Thessaloniki, P.O. Box 248, GR- \\ 54124, Greece
}

KEY WORDS: Fuel type mapping, Landsat-8 OLI, Object based image analysis, LUCAS points

\begin{abstract}
:
A key issue in modern fire management planning is the accurate fuel type mapping, required at many different spatial and temporal scales. Fuel type classification is critical for improving fire prevention schemes, developing accurate fire dispersion models and designing effective measures for mitigating the impacts of a potential wildfire event on the ecosystem. Remote sensing offers the potential to provide spatially distributed information on fuel types and it has been widely used both at regional and local scale. The aim of this study is to develop and evaluate a fuel type mapping methodology on a national level, based on the geographic objectoriented classification approach and Landsat-8 OLI imagery. The proposed methodology was developed in the case study of Chalkidiki in the northern part of Greece and it was further tested for its transferability in the regional unit of Preveza and the whole administrative region of Attica. The classification scheme was determined taking under consideration the existing fuel models (Prometheus, FBP etc) and fuel type products (JRC FUELMAP, LIFE10 ArcFUEL) so as the final fuel type map could be easily adjusted and/or compared. Fifty-four Landsat-8 OLI images for summer and for winter season, covering the national territory, were acquired and several features (vegetation indices, textural and spectral features) were calculated for both seasons. The optimized feature selection for the discrimination of each fuel type category was empirically obtained. Results showcase the effectiveness of the employed object-oriented classification approach in obtaining highly accurate fuel type maps. Specifically, the generated fuel map of Chalkidiki exhibited an overall accuracy of $89.47 \%$, with a Kappa Index of Agreement (KIA) equal to 0.844 . The application of the model to the two other regions resulted in overall accuracies of $80.30 \%$ (KIA=0.706) for Attica and 91.74\% (KIA=0.867) for Preveza. Summarizing, the results proved the good transferability properties of the proposed methodology enabling the implementation of the model across the country.
\end{abstract}

\section{INTRODUCTION}

Efficient forest fire management is the key element for alleviating the catastrophic impacts of wildfires, which involves both adequate planning and preparedness before the start of the fire season as well as a quantification of environmental impacts in case of wildfires (Martín-Gómez et al. 2015). Landscapelevel fuel maps are essential for local fire management, as they describe fire potential for planning and prioritizing specific burn incidents (Chuvieco et al. 1989). The design and consequent success of such measures is highly dependent on the availability and reliability of up-to-date fire-related data. The quality, completeness and reliability of such data need to be further and constantly improved, offering operational and procedural standardization and data interoperability (SanMiguel-Ayanz et al. 2012). Remote sensing offers the potential to provide spatially distributed information regarding the state of the managed areas and it has been widely used both at regional and local scale (Koetz et al. 2008). Traditionally, such generation of fuel maps has been based in the analysis of medium - to high- resolution sensors, such as Landsat MSS and TM data (Riaño et al. 2002). As a recent example of such effort is the fuel type methodology developed within the LIFE 2010 ArcFUEL project. Under the scope of the specific project, a fuel type map for four Mediterranean regions was generated based on Landsat TM imagery and pixel- based approach (Toukiloglou et al. 2013). Nevertheless, advanced classification methodologies such as object- oriented method, have been employed in several studies for local fuel type mapping in order to achieve more accurate results (Mallinis et al. 2014), (Arroyo et al. 2006), (Gitas et al. 2006). The aim of this study is to develop a methodology for fuel type mapping on a national level, using advanced classification techniques (Object Based Image Analysis-OBIA) and the newly Landsat 8 OLI imagery.

\section{STUDY AREA AND DATASET}

The fuel type mapping methodology was initially developed and tested in the case study of the Chalkidiki Regional Unit. The region is characterized as a typical Mediterranean area covered primarily with coniferous and beech forests, but also includes a variety of other habitats such as pastures, cultivations, streams and stony hills. In addition, the understory vegetation comprises maquis species and low herbaceous vegetation. The developed classification model was further applied to two other study areas, namely Attiki and Preveza, in order to test its transferability before implementing it on a national level.

The dataset employed for the analysis was the recently provided Landsat-8 OLI imagery. Particularly, fifty-four Landsat-8 OLI images - both during the summer and the winter seasons-were acquired, covering the whole country. To assist the classification, ancillary datasets were used such as the Land Identification Parcel System (LPIS) thematic layer, which is a geo-database that provides the accurate boundaries mainly of the agricultural areas as well as land parcels defined by natural breaks, provided by the Hellenic Agricultural Payments Organization (OPEKEPE) in accordance to the European Union's (EU) Common Agricultural Policy (CAP). The official 
vegetation layer provided by the Ministry of Environment and Energy was also used in this study. In addition, points from the Land Use and Cover Area frame Survey (LUCAS) provided by Eurostat on 2013, were employed for the accuracy assessment process.

\section{METHODOLOGY}

\subsection{Dataset pre-processing}

Pre-processing included a radiometric correction of the images converting the raw digital values into Top Of the Atmosphere (ToA) reflectance values (Mishra et al. 2014). Atmospheric correction was applied in order to enhance the classification outputs by employing the Dark Object Subtraction (DOS) technique (Gilmore et al. 2015). Finally, the two images per area, one for summer and one for winter season, were stacked together and a final image of 16 layers was generated. The dataset derived from that process will be henceforth referred as Landsat ${ }_{16 \text { bands. }}$

\subsection{Object-based image analysis}

A subset of the Landsat ${ }_{16 \text { bands }}$ covering the area of Chalkidiki was segmented using the multiresolution segmentation algorithm embedded in the commercial software eCognition Developer 8.7. Following the Fractal Net Evolution Approach (FNEA) concept (Baatz et al. 2000), three levels of segmentations were applied. In each level the segmentation parameters were determined empirically in order to produce highly homogenous objects in specific resolutions and for specific purposes. The classification scheme was determined taking under consideration the existing fuel models (Prometheus, FBP etc.) and fuel type products (JRC FUELMAP, LIFE10 ArcFUEL) so as the final fuel type map could be easily adjusted and/or compared. The fuel type categories classified per level were:

- $\quad$ Level 1: Agricultural areas, Urban areas

- $\quad$ Level 2: Non-vegetated areas, Waterbodies

- Level 3: Deciduous Broadleaves (three density classes: $0-40 \%, 41-70 \%$, and $71-100 \%$ ), Coniferous (three density classes as before), Evergreen Broadleaves (three density classes as before), Grasslands and Shrublands.

Classification was based on fuzzy logic rules, defined by means of fuzzy sets. A fuzzy set describes the degree of certainty to which an input pattern (object in this case) belongs to the class of the rule, with respect to the specific feature that it is defined for. The certainty degree for each feature value is derived through an appropriately defined membership function. Fuzzy rules are constructed by selecting a subset of features for each class and the final classification is derived as the class of the rule that exhibits the highest adaptation degree. In this study, a total number of 63 features was identified as a superset of features that can be potentially used to discriminate the categories of fuels (Table 1). Several vegetation indices were calculated from the images of both seasons (winter and summer), along with textural and spectral features embedded in the eCognition software. The subset of features involved in each fuzzy rule and the definition of the respective membership functions were determined empirically, as well as through expert knowledge.

\begin{tabular}{|c|c|c|}
\hline $\begin{array}{c}\text { Feature } \\
\text { Categories }\end{array}$ & Object Features & $\begin{array}{c}\text { Number of } \\
\text { Features }\end{array}$ \\
\hline $\begin{array}{l}\text { Customi- } \\
\text { zed } \\
\text { (Indices) }\end{array}$ & $\begin{array}{c}\text { DVI (s), DVI (w), MSAVI2 } \\
\text { (s), MSI (s), NDVI (s), NDVI } \\
\text { (w), NDWI (s), RVI (s), RVI } \\
\text { (w), SAVI (s), SAVI (w), } \\
\text { SUM, VIN (s), VIN (w), } \\
\text { Minus NDVI }\end{array}$ & 15 \\
\hline $\begin{array}{l}\text { Layer } \\
\text { Values }\end{array}$ & $\begin{array}{l}\text { Brightness, Max. Difference, } \\
\text { Mean (for all image layers), } \\
\text { Standard Deviation (for all } \\
\text { image layers), Ratio (for the } \\
\text { image layers Blue (s), Green } \\
\text { (s), Red (s), NIR (s), SWIR1 } \\
\text { (s), SWIR2 (s)), Min pixel } \\
\text { value (for the image layers } \\
\text { Green (s), NIR (s)), Border } \\
\text { Contrast (for the image layers } \\
\text { Blue (s), NIR (s)), Circular } \\
\text { Mean (for the image layers } \\
\text { Blue (s), NIR (s), NIR (w), } \\
\text { Red (s)) }\end{array}$ & 44 \\
\hline Geometry & $\begin{array}{l}\text { Border length, Length/Width, } \\
\text { Compactness, Roundness }\end{array}$ & 4 \\
\hline $\begin{array}{c}\text { Total } \\
\text { amount }\end{array}$ & & 63 \\
\hline
\end{tabular}

(s) and (w) denote features derived from summer and winter season images, respectively.

Table 1. List of object features divided into three categories according to eCognition's categorization.

To test the transferability of the developed methodology we applied the object-based classification model in other two study areas, namely Attiki and Preveza. Those areas were selected since they present differences in the fuel type's distribution. Apart from some adjustments in the parameters' values of some fuzzy sets, the classification model's structure (e.g., number rules, features selected for each rule, etc.) was maintained. Subsequently, the model was applied to the rest of the country, in order to obtain the whole fuel type map.

\subsection{Accuracy Assessment}

The final products were evaluated for their accuracy, using the confusion matrix method (Foody 2002). A total set of 7626 LUCAS points (2013) covering the Greek territory was used as control points in the accuracy assessment process. At this point it should be mentioned that the agricultural and urban areas that were classified using the LPIS thematic layer, were excluded from the accuracy assessment process.

\section{RESULTS}

The derived fuel type maps of Chalkidiki, Attiki and Preveza are depicted in Figure 1 and the national fuel type map in Figure 2. The Overall Accuracy (OA) of the final map showed that the classification exhibits very satisfactory results in terms of overall performance and kappa coefficient $(\mathrm{OA}=87.80 \%$ and kappa $=0.837)$. Particularly, in Chalkidiki, where the classification model was developed, the overall accuracy was equal to $89.47 \%(\mathrm{KIA}=0.844)($ Fig1a). Results showed that the transferability of the model in the next two study areas seemed to be well adjustable, with OA equal to $89.28 \%(\mathrm{KIA}=0.839)$ 
(Fig $1 \mathrm{~b}$ ) in the study area of Attiki and OA equal to $91.74 \%$ $(\mathrm{KIA}=0.868)$ in the study area of Preveza (Fig1c) (Table 2).
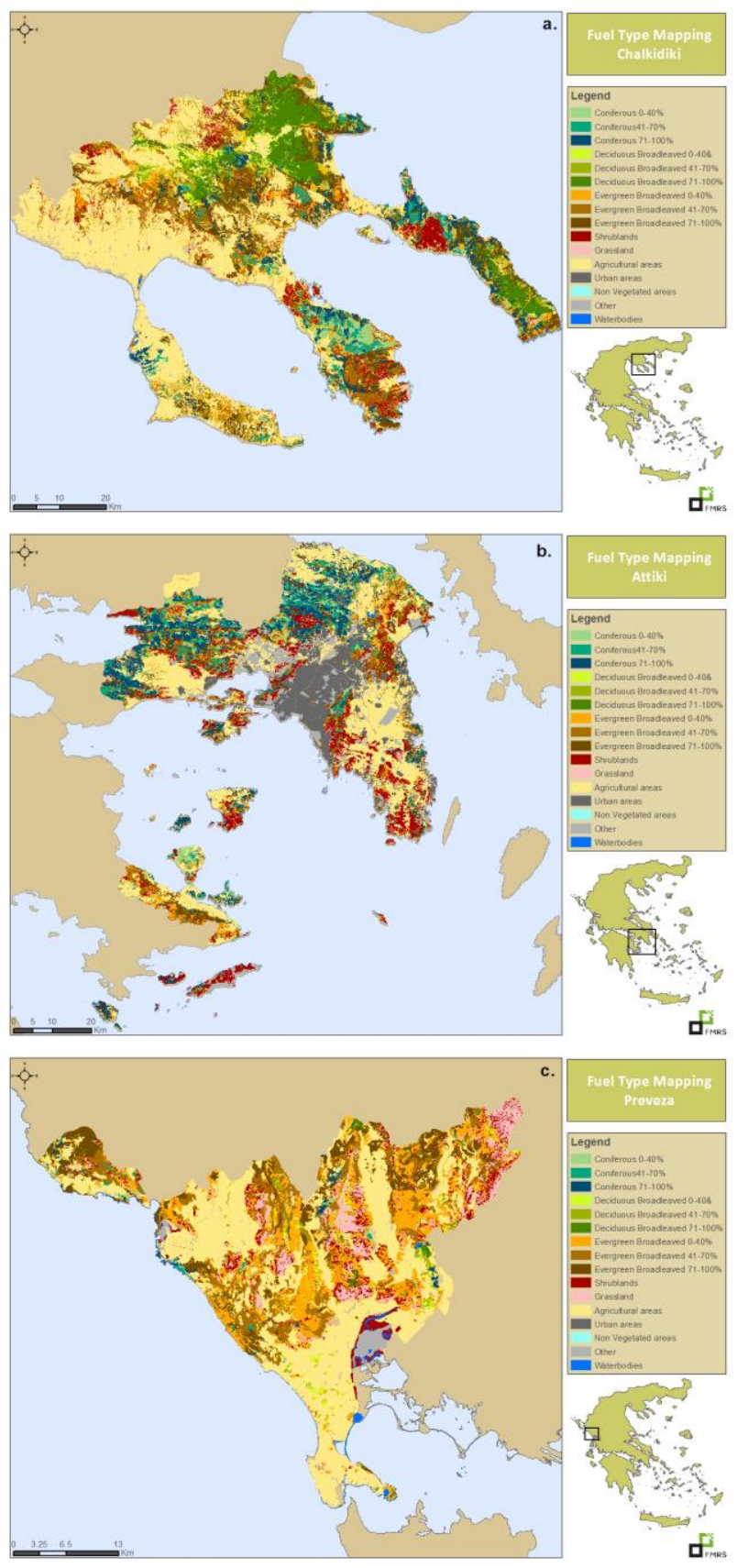

Figure 1. Fuel type classifications for the three study areas. The object-based classification model was developed in the first area of Chalkidiki (a) and it was further tested for its transferability in the other areas, Attiki (b) and Preveza (c) in accordance.

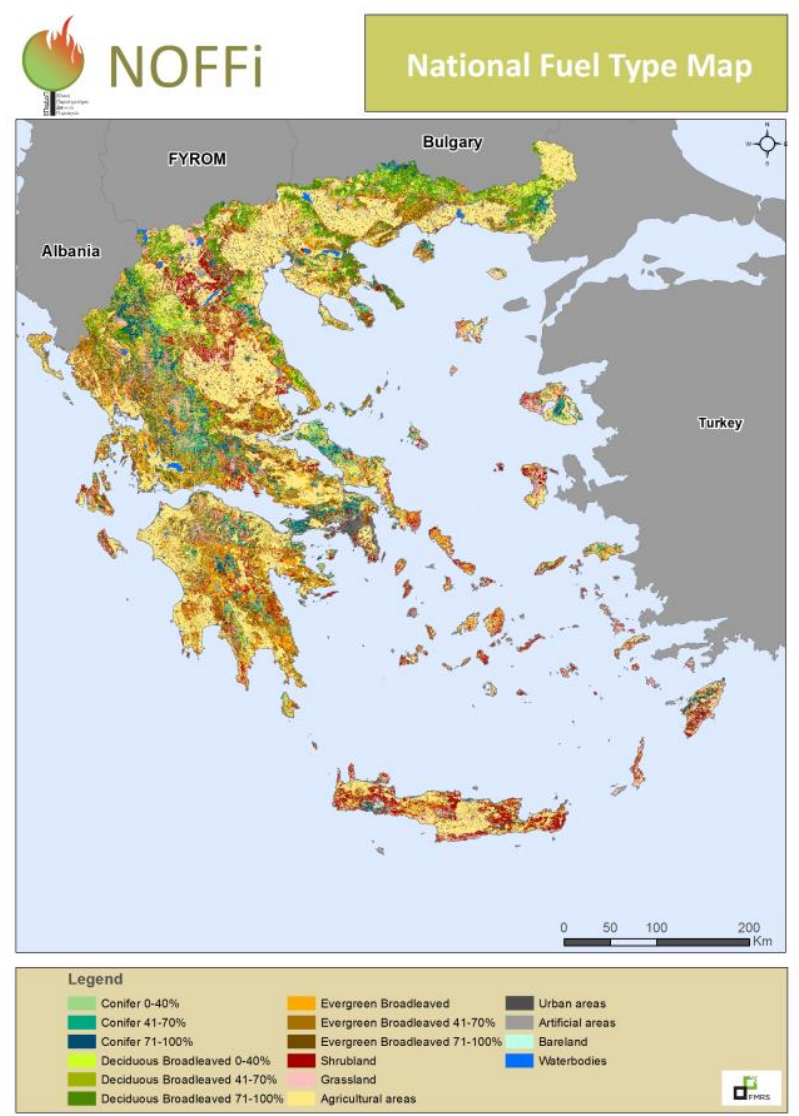

Figure 2. National fuel type map produced by object-based image analysis and Landsat 8 OLI imagery.

\begin{tabular}{|c|c|c|c|c|}
\cline { 2 - 5 } \multicolumn{2}{c|}{} & Chalkidiki & Attiki & Preveza \\
\hline \multirow{2}{*}{$\begin{array}{c}\text { Deciduous } \\
\text { Broadleaved }\end{array}$} & $U A$ & 97.53 & N/A & 83.33 \\
\cline { 2 - 5 } & $P A$ & 96.34 & N/A & 74.07 \\
\hline \multirow{2}{*}{ Coniferous } & $U A$ & 86.11 & 86.79 & 76.47 \\
\cline { 2 - 5 } & $P A$ & 74.7 & 97.18 & 100 \\
\hline \multirow{2}{*}{$\begin{array}{c}\text { Evergreen } \\
\text { Broadleaved }\end{array}$} & $U A$ & 88.06 & 91.28 & 94.39 \\
\cline { 2 - 5 } & $P A$ & 92.19 & 82.93 & 92.96 \\
\hline \multirow{2}{*}{ Grassland } & $U A$ & 85.71 & 80.00 & 92.86 \\
\cline { 2 - 5 } & $P A$ & 85.71 & 100 & 88.64 \\
\hline \multirow{2}{*}{ Shrubland } & $U A$ & 83.87 & 90.12 & 84.62 \\
\cline { 2 - 5 } & $P A$ & 92.86 & 86.90 & 97.06 \\
\hline \multirow{2}{*}{ Unvegetated } & $U A$ & 100 & 100 & 100 \\
\cline { 2 - 5 } & $P A$ & 100 & 100 & 90.91 \\
\hline \multirow{2}{*}{\begin{tabular}{c} 
Waterbodies \\
\cline { 2 - 5 }
\end{tabular}} & UA & 100 & 100 & 100 \\
\hline $\begin{array}{c}\text { Kappa } \\
\text { Coefficient }\end{array}$ & 100 & 100 & 100 \\
\hline $\begin{array}{c}\text { Overall } \\
\text { Accuracy } \%)\end{array}$ & & $\mathbf{8 9 . 4 7}$ & $\mathbf{8 9 . 2 8}$ & $\mathbf{9 1 . 7 4}$ \\
\hline
\end{tabular}

Table 2. User's accuracies (UA) and Producer's accuracies (PA) of the three classifications.

In the case of Chalkidiki, the results in general, show high values of PA and UA in all classes. This is expected since the model was developed based on the specific area. Apart from 
"Unvegetated" and "Waterbodies", that were accurately classified, the "Deciduous Broadleaves" present the highest PA and UA with minor of $2 \%$ deviation. However, in the case of Preveza, the specific class is underestimated. A closer examination of the map revealed that the misclassified objects were mainly located in shadowed areas (mainly shadows from the rough terrain). On the other hand, "Coniferous" seem to be overestimated since their spatial distribution is rather sparse resulting to spectral heterogeneity. What is commonly observed in all three cases is the underestimation and overestimation of "Grassland" and "Shrubland" classes, which can be attributed to two conditions. First, many small areas (even comparable to the pixel size) are characterized by complex patterns comprising both types of vegetation. For example, in typical grassland several individual shrubs are scattered, whereas areas of low vegetation are frequently observed within shrublands. Secondly, such intermixing often occurs in areas smaller than the pixel size, resulting in the existence of mixed pixels. This in turn leads to the creation of rather spectral heterogeneous objects during the segmentation process.

\section{CONCLUSIONS}

In this study, we develop an object oriented methodology for accurate fuel type mapping on a national level. The classification procedure was developed based on Landsat 8 OLI imagery for summer and winter season. Initially, the classification model was developed in the study area of Chalkidiki. In further, it was applied in other two areas, namely Attiki and Preveza in order to test and evaluate its transferability. Summarizing, the results showcase the effectiveness of the employed object-oriented classification approach in obtaining highly accurate fuel type maps for operational use on a national level.

\section{ACKNOWLEDGEMENTS}

This research work was conducted as part of the project "National Observatory of Forest Fires (NOFFi)", which is implemented in collaboration with the Directorate General for the Development and Protection of Forests and Rural Environment of the Hellenic Ministry of Environment and Energy and financially supported by Greece's Green Fund.

\section{REFERENCES}

Arroyo, L. A., S. P. Healey, et al. (2006). "Using object-oriented classification and high-resolution imagery to map fuel types in a Mediterranean region." Journal of Geophysical Research: Biogeosciences (2005-2012) 111(G4).

Baatz, M. and A. Schäpe (2000). "Multiresolution segmentation: an optimization approach for high quality multiscale image segmentation." Angewandte Geographische Informationsverarbeitung XII: 12-23.

Chuvieco, E. and R. G. Congalton (1989). "Application of remote sensing and geographic information systems to forest fire hazard mapping." Remote sensing of Environment 29(2): 147-159.

Foody, G. M. (2002). "Status of land cover classification accuracy assessment." Remote Sensing of Environment 80(1): 185-201.
Gilmore, S., A. Saleem, et al. (2015). "Effectiveness of DOS (Dark-Object Subtraction) method and water index techniques to map wetlands in a rapidly urbanising megacity with Landsat 8."

Gitas, I., G. Mitri, et al. (2006). "Fuel type mapping in Anopolis, Crete by employing QuickBird imagery and objectbased classification." Forest Ecology and Management 234(1): S228.

Koetz, B., F. Morsdorf, et al. (2008). "Multi-source land cover classification for forest fire management based on imaging spectrometry and LiDAR data." Forest Ecology and Management 256(3): 263-271.

Mallinis, G., G. Galidaki, et al. (2014). "A comparative analysis of EO-1 Hyperion, Quickbird and Landsat TM imagery for fuel type mapping of a typical Mediterranean landscape." Remote Sensing 6(2): 1684-1704.

Martín-Gómez, C., J. Vergara-Falces, et al. (2015). "Geographic information system software application developed by a regional emergency agency." Case Studies in Fire Safety 4: 1927.

Mishra, N., M. O. Haque, et al. (2014). "Radiometric Cross Calibration of Landsat 8 Operational Land Imager (OLI) and Landsat 7 Enhanced Thematic Mapper Plus (ETM+)." Remote Sensing 6(12): 12619-12638.

Riaño, D., E. Chuvieco, et al. (2002). "Generation of fuel type maps from Landsat TM images and ancillary data in Mediterranean ecosystems." Canadian Journal of Forest Research 32(8): 1301-1315.

San-Miguel-Ayanz, J., E. Schulte, et al. (2012). "Comprehensive monitoring of wildfires in Europe: the European Forest Fire Information System (EFFIS)."

Toukiloglou, P., G. Eftychidis, et al. (2013). ArcFuel methodology for mapping forest fuels in Europe. First International Conference on Remote Sensing and Geoinformation of Environment, International Society for Optics and Photonics. 